NURUL HASANAH KUSUMAH DEWI DAN WAWAN DARMAWAN

LUDO HISTORY (DORY) DALAM PEMBELAJARAN SEJARAH DI SMA NEGERI 7 BANDUNG

\title{
LUDO HISTORY (DORY) DALAM PEMBELAJARAN SEJARAH DI SMA NEGERI 7 BANDUNG
}

\author{
Oleh \\ Nurul Hasanah Kusumah Dewi dan Wawan Darmawan ${ }^{1}$
}

\begin{abstract}
This research emerged from researcher concern regarding student's lack of conceptual comprehension at Grade 11 Social Science 3 - Senior Highschool 7 Bandung. The indicator to measure conceptual understanding in this research is to read the trusted source about the contents, knowing the concepts, explaining the concepts, analogizing the concepts, classifying the concepts, and connecting the concepts. This research used the classroom action research designed by Kemmis and McTaggart which consists of four stages: planning, acts, observation and reflection. According to result analysis, there is an increase on every cycle in the student's development to reach the criteria of concept comprehension indicator, this can be seen by looking at the scores on every indicator in each cycle. Therefore, it shows the achievement when applying a game called "Ludo History" in increasing student's conceptual understanding. Moreover, by looking at the results, the game Ludo History (Dory) can become one of the alternatives to learning problems in the classroom.
\end{abstract}

Keywords: Classroom Action Research, Conceptual Comprehension, Ludo History (Dory)

\section{PENDAHULUAN}

Pelaksanaan proses pembelajaran tidak dapat terlepas dari komponenkomponen pembelajaran. Mengenai komponen-komponen pembelajaran, Hamalik (dalam Falahudin, 2014, hlm. 104) mengemukakan bahwa:

terdapat lima komponen yang sangat penting adalah tujuan, materi, metode, media, dan evaluasi pembelajaran. Kelima aspek ini saling mempengaruhi. Pemilihan salah satu metode mengajar tertentu akan berdampak pada jenis media pembelajaran yang sesuai, dengan tanpa melupakan tiga aspek penting lainnya. Dalam hal ini dapat dikatakan bahwa salah satu fungsi utama media pembelajaran adalah sebagai alat bantu mengajar yang turut mempengaruhi motivasi, kondisi, dan lingkungan belajar.

Mengacu kepada pendapat Hamalik mengenai media pembelajaran, dapat diketahui bahwa sebagai salah satu komponen pembelajaran, media pembelajaran memiliki peran penting yang di antaranya adalah membangkitkan motivasi belajar dan memberikan pengaruh pada lingkungan belajar siswa. Hal ini didukung oleh hasil penelitian Hafid (2011, hlm. 7), ia menjelaskan bahwa

${ }^{1}$ Nurul Hasanah Kusumah Dewi adalah mahasiswa pada Departemen Pendidikan Sejarah FPIPS UPI. Wawan Darmawan adalah dosen pembimbing I. Penulis dapat dihubungi di email : urulhasanahkusumahdewi@gmail.com. 
media pembelajaran sedikit banyak akan meningkatkan intensitas pembelajaran. Proses pembelajaran dipermudah dan pembelajaran menjadi semakin menarik. Pendapat yang selaras juga dikemukakan oleh Maimunah (2016, hlm. 23), ia mengemukakan bahwa penggunaan media pembelajaran sangatlah besarpengaruhnya dalam meningkatkan perhatian, motivasi, dan peningkatan kualitas pembelajaran.

Pentingnya penggunaan media dalam pembelajaran serta peranan media pembelajaran yang dikemukakan oleh Hafid dan Maimunah membuktikan bahwa efektivitas proses belajar mengajar di kelas turut ditentukan oleh penggunaan media pembelajaran. Proses belajar mengajar khususnya pada mata pelajaran sejarah seringkali dihadapkan pada materi yang abstrak dan berada di luar pengalaman siswa dalam kehidupan sehari-hari sehingga berbagai materi tersebut membutuhkan komponen media pembelajaran agar materi yang semula bersifat abstrak dapat menjadi lebih konkrit dan mudah dipahami oleh siswa. Pendapat ini selaras dengan pendapat Antopani (2016, hlm. 12) yang menjelaskan bahwa:

berbicara pembelajaran sejarah, maka komponen media sangatlah diperlukan. Mengingat objek dari pelajaran sejarah terpisah jauh dari masa sekarang. Perbedaan waktu yang jauh itu menimbulkan kesulitan tersendiri, yaitu lebih abstrak. Dengan adanya media pembelajaran diharapkan materi sejarah menjadi lebih kongkrit dan bermakna bagi peserta didik.

Mengenai penggunaan media dalam pembelajaran sejarah, Alvionita (2014, hlm. 34) pun berpendapat, ia menjelaskan bahwa:

dalam proses belajar mengajar khususnya mata pelajaran sejarah, penggunaan media berperan sangat penting terhadap transformasi materi yang diberikan oleh guru kepada muridnya karena pelajaran sejarah mempunyai materi yang sangat luas dan kompleks sehingga perlu adanya media pembelajaran agar tujuan pembelajaran dapat tercapai dan hasil belajar siswa menjadi baik.

Berbagai media dapat digunakan oleh guru dalam pembelajaran sejarah, salah satunya adalah media permainan. Permainan dapat menjadi salah satu alternatif yang digunakan untuk meraih tujuan pembelajaran serta meningkatkan keterlibatan siswa dalam proses pegalaman belajar sekaligus menghayati tantangan, medapatkan inspirasi, terdorong untuk kreatif dan berinteraksi dalam melakukan permainan. Pernyataan ini selaras dengan pendapat Smaldino (2008, hlm. 39) yang mengemukakan bahwa:

permainan memberikan lingkungan kompetitif yang di dalamnya para pemelajar mengikuti aturan yang telah ditetapkan saat mereka berusaha mencapai tujuan pendidikan yang menantang. Ini merupakan teknik yang sangat memotivasi, terutama untuk konten yang membosankan dan repetitif. Permainan mungkin melibatkan satu pemelajar atau satu kelompok pemelajar. Permainan sering kali mengharuskan para pemelajar untuk menggunakan keterampilan menyelesaikan masalah, kemampuan menghasilkan solusi atau memperlihatkan penguasaan atas 
NURUL HASANAH KUSUMAH DEWI DAN WAWAN DARMAWAN

LUDO HISTORY (DORY) DALAM PEMBELAJARAN SEJARAH DI SMA NEGERI 7 BANDUNG

konten spesifik yang mengharuskan tingkat akurasi dan efisiensi yang tinggi.

Mengacu dari pendapat Smaldino, terdapat beberapa hal yang dapat dianggap sebagai kelebihan penggunaan media pembelajaran berupa permainan, di antaranya adalah media permainan dapat memotivasi siswa, melatih keterampilan penyelesaian masalah, kemampuan menghasilkan solusi serta memperlihatkan penguasaan konten yang spesifik.

Media permainan pun dapat menjadi alternatif solusi dalam memecahkan masalah yang ditemui oleh guru dalam pembelajaran sejarah, salah satunya ialah masalah yang berkaitan dengan pemahaman konsep. Materi sejarah seringkali memuat konsep-konsep yang abstrak dan jarang ditemui oleh siswa di kehidupan sehari-hari. Hal ini mengindikasikan bahwa konsep menjadi satu hal yang penting bagi setiap siswa. Pemahaman mengenai konsep akan membantu siswa melakukan proses pembelajaran yang berkelanjutan.

Selain itu, pemahaman konsep juga akan membantu siswa untuk menelaah dan mengidentifikasi permasalahan yang terjadi di masyarakat. Meskipun begitu, proses pembelajaran sejarah di kelas XI IPS 3 di SMAN 7 Bandung kurang menekankan kepada pemahaman konsep siswa. Selain itu, pembelajaran sejarah yang lebih sering dilaksanakan merupakan pembelajaran yang masih bersifat teacher centered sehingga pemahaman konsep pada mata pelajaran sejarah yang dimiliki oleh siswa terbatas pada apayang dijelaskan oleh guru. Peneliti juga melihat bahwa karakteristik kelas adalah aktif dalam aspek kinestetik, maka dari itu peneliti berasumsi bahwa media pembelajaran berbasis permainan tepat digunakan untuk meningkatkan pemahaman konsep siswa. Alasan lain yang menjadi pertimbangan bagi peneliti untuk memilih media permainan adalah karena media permainan merupakan jenis media yang belum pernah digunakan oleh guru sejarah di kelas penelitian.

Anggapan peneliti mengenai penggunaan media permainan merupakan solusi yang tepat untuk meningkatkan pemahaman konsep mengacu pada pendapat Fauziah (2017, hlm. 2) yang mengemukakanbahwamelaluipenggunaan media, beragam konsep dapat disampaikan dengan efektif dan menjadikan suatu pembelajaran yang disenangi serta mudah diingat oleh peserta didik. Adapun media permainan yang disusun oleh peneliti adalah media permainan Ludo History (Dory). Dory merupakan permainan Ludo yang telah dimodifikasi sedemikian rupa yang bertujuan untuk meningkatkan pemahaman konsep siswa pada mata pelajaran Sejarah. Teknis permainan yang tergambar dalam peraturan Dory di desain untuk menumbuhkan minat belajar siswa dan meningkatkan pemahaman konsep siswa dalam waktu yang sama. Keadaan di mana siswa mengenali, mendengarkan, dan melihat saat dilakukannya permainan dapat menjadikan siswa dapat lebih banyak mengingat apa yang telah dipelajari.

\section{METODE PENELITIAN}

Metode yang digunakan dalam penelitian ini adalah metode Penelitian Tindakan Kelas (PTK). Hopkins (dalam Hasan, dkk, 2011, hlm. 72) mendefinisikan Penelitian Tindakan Kelas sebagai kegiatan yang dilakukan guru untuk menumbuhkan kualitas mengajarnya atau kualitas 
mengajar teman sejawat atau menguji asumsi-asumsi dari teori-teori pendidikan dalam prakteknya di kelas. Berkaitan dengan pendapat Hopkins, Arikunto (2008, hlm 3) mengemukakan bahwa Penelitian Tindakan Kelas merupakan suatu pencermatan terhadap kegiatan belajar berupa sebuah tindakan, yang sengaja dimunculkan dan terjadi dalam sebuah kelas secara bersama.

Senada dengan pendapat Hopkins dan Arikunto, Suyanto dalam (Muslich, 2009, hlm. 9) menjelaskan bahwa Penelitian Tindakan Kelas adalah suatu bentuk penelitian yang bersifat reflektif dengan melakukantindakan-tindakantertentuagar dapat memperbaiki atau meningkatkan praktik-praktik pembelajaran di kelas secara professional. Kemudian Kunandar (2012, hlm. 63) pun menjelaskan bahwa Penelitian Tindakan Kelas bertujuan untuk memecahkan permasalahan nyata yang terjadi di dalam kelas yang dialami langsung dalam interaksi antara guru dan siswa yang sedang belajar.

Adapun desain penelitian yang digunakan adalah desain penelitian model Kemmis dan Mc. Taggart dengan empat komponen penelitian tindakan, yakni perencanaan (plan), tindakan (action), observasi (observe) dan refleksi (reflection). Dengan menggunakan desain penelitian tindakan kelas yang dirancang oleh Kemmis dan McTaggart dalam penelitian ini satu siklus dilaksanakan dalam satu tindakan, dengan pelaksanaan tahap tindakan yang dilakukan dalam dua pertemuan.

Alat pengumpul data yang digunakan dalam penelitian ini adalah lembar observasi, catatan lapangan, dan pedoman wawancara. Kemudian teknik pengumpulan data yang digunakan dalam penelitian ini berupa observasi, wawancara dan studi dokumentasi. Setelah data terkumpul, kegiatan yang dilakukan selanjutnya adalah mengolah data tersebut. Di dalam pelaksanaan penelitian tindakan kelas ini, ada dua jenis data yang dikumpulkan yaitu kualitatif dan kuantitatif.

Berdasarkan data yang diperoleh pada proses penelitian perlu adanya pengujian dan analisis data. Pada penelitian ini, cara yang dilakukan untuk menguji validasi yaitu dengan melakukan triangulasi, audit trail, member check dan expert opinion.

\section{HASIL PENELITIAN DAN PEMBAHASAN}

Media permainan Dory adalah permainan Ludo yang digunakan setelah dimodifikasi sesuai dengan kebutuhan. Dory dimodifikasi untuk meningkatkan pemahaman konsep siswa pada mata pelajaran Sejarah dengan sedikit penggabungan dari permainan monopoli dengan mengambil bentuk permainan yang menggunakan beberapa kartu yang dalam hal ini berupa kartu pertanyaan yang harus dijawab oleh siswa dan beberapa kartu "bonus" yang isinya serupa dengan kartu "dana umum atau kesempatan" dalam permainan monopoli.

Kartu-kartu tersebut akan diterima oleh setiap siswa atau pemain ketika menginjakkan kaki di setiap kotak dalam permainan Dory, terkecuali kotak yang memiliki tanda bintang. Adapun mengenai bentuknya, Dory menggunakan versi ludo dengan enam pemain seperti yang dikembangkan oleh sebuah game yang bernama Ludo King. Enam pemain dalam permainan Ludo King direpresentasikan 
ke dalam enam kelompok - dengan satu kelompok terdiri dari lima orang - dalam permainan Dory. Dengan kata lain Dory merupakan permainan Ludo yang diperbesar agar seluruh siswa dapat bermain dalam satu waktu.

Untuk memainkan Dory, dibutuhkan peraturan dan teknis permainan agar Dory bisa berlangsung dengan efisien. Berikut adalah aturan permainan dan teknis permainan Dory.

1. Peraturan Umum

a. Guru bertugas memimpin jalannya permainan. Selama permainan berlangsung guru berperan sebagai pembaca kartu permainan serta juri dalam permainan. Penjurian tersebut dibantu oleh para ketua kelompok yang ikut memperhatikan jawaban setiap kelompok untuk mengetahui apakah jawaban yang dikemukakan oleh kelompok tersebut benar atau salah.

b. Seluruh siswa mendapat kesempatan untuk menjadi pemain. Pemain terdiri dari enam kelompok yang masingmasing terdiri dari lima orang. Setiap kelompok terdiri dari satu orang ketua dan empat anggota sebagai pion

c. Tugas ketua adalah mengatur pion-pion dalam kelompoknya, melempar dadu serta membantu pion-pion kelompok dalam menjawab pertanyaan. Ketua memiliki hak istimewa untuk membuka buku (hanya tiga kali) untuk membantu pion-pion kelompok dalam menjawab pertanyaan. Anggota atau pion tidak diperbolehkan membuka buku atau internet. Ketua dapat menggunakan hak untuk membuka buku setelah dizinkan oleh guru selaku pemimpin permainan. d. Selama permainan berlangsung, semua pemain harus berada dalam karpet Dory, jika terdapat pemain yang berpindah dari tempatnya tanpa izin guru, maka pemain tersebut akan mendapatkan poin -5

e. Angka dadu yang didapat menentukan jumlah langkah pion

f. Seluruh kotak dalam Dory memiliki kartu pertanyaan yang harus dijawab oleh pion atau ketua kelompok serta "kartu bonus"

2. Langkah Bermain

a. Permainan akan berlangsung selama 75 menit.

b. Sebelum bermain Dory, setiap kelompok harus mengisi LKS yang terdiri dari lima soal. Skor LKS akan menentukan berapa pion yang bermain dalam sebuah kelompok pada putaran pertama.

c. Pemain harus melepaskan sepatunya masing-masing sebelum memasuki karpet Dory

d. Langkah bermainnya adalah: ketua memilih pion - pion menempati sebuah kotak - pion menerima kartu (kartu yang diterima dapat berupa pertanyaan atau "kartu bonus" jika kartu yang didapat adalah kartu pertanyaan maka pion dipersilahkan menjawab pertanyaan tersebut - jika jawabannyabenar maka pion mendapat kesempatan untuk melempar dadu dan melangkah, jika jawabannya salah maka pion tidak mendapat kesempatan untuk melempar dadu dan melangkah pada giliran tersebut

e. Setiap kotak tidak bisa ditempati oleh 2 pion yang berbeda kelompok sehingga bila ada pion yang menempatidua kotak 
maka pion pertama yang menempati kotak akan ditabrak dan harus kembali ke home. Pion yang menabrak berhak mendapat kesempatan untuk mengocok dadu lagi.

f. Pemain aman (tidak mendapat pertanyaan dan tidak berlaku sistem mati) saat berada di kotak "bintang"

g. Waktu menjawab kartu pertanyaan adalah 30 detik, jika pertanyaan tidak terjawab maka pertanyaan tersebut akan menjadi pertanyaan yang berhak dijawab oleh kelompok pada giliran selanjutnya

h. Satu kartu pertanyaan bernilai 10 poin (jika dijawab benar). Namun terdapat kartu yang bernilai 30 poin (tergantung tingkat kesukaran soal)

i. Jika terdapat pion yang mencapai finish maka kelompok tersebut mendapat poin tambahan 10

j. Pemenang adalah kelompok yang paling banyak mendapatkan poin
Adapun mengenai hasil temuan di lapangan, yaitu selama melakukan penelitian mengenai penerapan media permainan Dory untuk meningkatkan pemahaman konsep siswa dalam pembelajaran sejarah, peneliti mendapatkan hasil bahwa pemahaman konsep siswa mengalami peningkatan pada setiap siklusnya. Peningkatan pemahaman konsep siswa dalam setiap siklus tersebut dapat terlihat dari rata-rata perolehan skor kelompok yang dijabarkan dalam tabel 9.1.

Berdasarkan data tersebut, terlihat bahwa tidak ada indikator pemahaman konsep yang mengalami penurunan skor. Kemudian pada siklus I rata-rata skor pemahaman konsep siswa adalah 9,8 dan masuk ke dalam kategori nilai kurang baik. Kemudian pada siklus II mengalami peningkatan menjadi 11,6 dan masuk ke dalam kategori cukup baik, kemudian pada siklus III mengalami peningkatan sehingga diperoleh ratarata perolehan skor pemahaman konsep kelompok siswa menjadi 14,3 dengan

Tabel 11.1 Hasil Observasi Pemahaman Konsep Siswa

\begin{tabular}{|c|c|c|c|c|}
\hline No & Indikator & Siklus I & Siklus II & $\begin{array}{l}\text { Siklus } \\
\text { III }\end{array}$ \\
\hline 1. & $\begin{array}{l}\text { Membaca sumber terpercaya mengenai } \\
\text { materi yang sedang dipelajari }\end{array}$ & 10 & 12 & 15 \\
\hline 2. & Mengenal konsep-konsep & 13 & 14 & 15 \\
\hline 3. & Menjelaskan konsep-konsep & 12 & 12 & 15 \\
\hline 4. & Memberikan contoh dari konsep & 6 & 9 & 13 \\
\hline 5. & Mengklasifikasikan konsep-konsep & 9 & 12 & $\underline{13}$ \\
\hline 6. & Menghubungkan konsep- konsep & 9 & 11 & 15 \\
\hline \multicolumn{2}{|c|}{ Jumlah skor Siklus } & 59 & 70 & 86 \\
\hline \multicolumn{2}{|c|}{ Skor Maksimal } & \multicolumn{3}{|c|}{108} \\
\hline \multicolumn{2}{|c|}{ Konversi Nilai } & Cukup Baik & Cukup Baik & Baik \\
\hline \multicolumn{2}{|c|}{ Persentase } & $55 \%$ & $65 \%$ & $80 \%$ \\
\hline
\end{tabular}


NURUL HASANAH KUSUMAH DEWI DAN WAWAN DARMAWAN LUDO HISTORY (DORY) DALAM PEMBELAJARAN SEJARAH DI SMA NEGERI 7 BANDUNG

Tabel 11.2 Hasil Skor Pemahaman Konsep Siswa dari Siklus I hingga Siklus III

\begin{tabular}{|c|c|c|c|c|c|c|}
\hline Kelompok & $\begin{array}{c}\text { Skor Siklus } \\
\text { I }\end{array}$ & Kriteria & $\begin{array}{c}\text { Skor Siklus } \\
\text { II }\end{array}$ & Kriteria & $\begin{array}{c}\text { Skor Siklus } \\
\text { III }\end{array}$ & Kriteria \\
\hline$\underline{I}$ & $\underline{12}$ & Cukup Baik & $\underline{11}$ & Cukup Baik & 15 & Baik \\
\hline$\underline{\text { II }}$ & $\underline{8}$ & Cukup Baik & $\underline{11}$ & Cukup Baik & 13 & $\underline{\text { Baik }}$ \\
\hline$\underline{\text { III }}$ & $\underline{10}$ & Cukup Baik & 13 & $\underline{\text { Baik }}$ & $\underline{14}$ & $\underline{\text { Baik }}$ \\
\hline$\underline{\text { IV }}$ & $\underline{11}$ & Cukup Baik & 13 & Baik & $\underline{16}$ & Baik \\
\hline$\underline{\mathrm{V}}$ & $\underline{11}$ & Cukup Baik & $\underline{12}$ & Cukup Baik & $\underline{16}$ & Baik \\
\hline$\underline{\mathrm{VI}}$ & $z$ & Cukup Baik & $\underline{10}$ & Cukup Baik & $\underline{12}$ & Cukup Baik \\
\hline$\frac{\text { Rata-Rata }}{\underline{\text { Skor }}}$ & 9,8 & Cukup Baik & $\underline{11,6}$ & Cukup Baik & 14.3 & $\underline{\text { Baik }}$ \\
\hline
\end{tabular}

kriteria nilai baik. Rata-rata perolehan skor setiap siklus diperoleh dari ratarata skor setiap kelompok pada setiap siklus. Peningkatan rata-rata perolehan skor tersebut menunjukkan bahwa penerapan media permainan Dory mampu meningkatkan pemahaman konsep siswa dalam pembelajaran sejarah. Hasil penemuan ini membuktikan keyakinan peneliti bahwa media permainan Dory dapat menjadi alternatif solusi untuk meningkatkan pemahaman konsep siswa. Hal ini selaras dengan pendapat Arikunto (2008, hlm. 56-57) yang mengemukakan bahwa penelitian tindakan bukan lagi mengetes sebuah perlakuan, tetapi sudah mempunyai keyakinan akan ampuhnya sesuatu perlakuan. Pada penelitian tindakan peneliti mencermati kajiannya pada proses dan akibat dari tindakan yang dibuatnya. Berdasarkan hasil pencermatan itu, dapat dilakukan tindakan berikutnya sehingga diperoleh informasi yang mantap tentang dampak tindakan. Selain itu, hasil temuan peneliti dalam penelitian ini pun dapat membuktikan hasil penelitian Fauziah (2017, hlm.2) yang berisi bahwa melalui penggunaan media, beragam konsep dapat disampaikan dengan efektif dan menjadikan suatu pembelajaran yang disenangi serta mudah diingat oleh siswa.
Peningkatan pemahaman konsep dalam pembelajaran sejarah pada penelitian ini tentu dipengaruhi pula oleh beberapa faktor di antaranya adalah media permainan Dory menciptakan kegiatan belajaryang aktif sehingga kesempatan bagi siswa untuk mengkostruksi pemikirannya untuk menjadi awal pembentukan pemahaman konsep terbuka. Seperti yang dijelaskan oleh Tendrita, dkk (2016, hlm. 214) yang menjelaskan bahwa salah satu cara agar siswa mudah memahami konsep yaitu dengan melibatkan siswa secara aktif dalam pembelajaran. Pembelajaran yang melibatkan siswa aktif dapat meningkatkan kemampuan berpikir siswa dalam memahami sebuah konsep serta dapat menyelesaikan masalah dengan keterampilan-keterampilan dan ilmu pengetahuan yang telah dimiliki.

Kegiatan belajar yang aktif dan memberikan ruang bagi siswa untuk berkontribusi langsung dalam pembelajaran menjadi faktor pendukung peningkatan pemahaman konsep melalui media permainan Dory karena proses pembelajaran yang berpusat pada guru dapat menjadi salah satu penyebab rendahnya pemahaman konsep siswa. Seperti yang dijelaskan oleh Saragih (dalam Erlandini, 2017, hlm. 3) bahwa salah satu 
penyebab rendahnya pemahaman konseep siswa adalah proses pembelajaran yang bepusat pada guru, siswa tidak terlibat dalam mengkonstruksi pengetahuannya karena hanya menerima informasi yang disampaikan searah dari guru.

Selain meningkatkan pemahaman konsep siswa, peneliti menemukan bahwa penerapan media permainan Dory ini juga meningkatkan kerja sama antar siswa karena Dory membutuhkan kerja sama antar anggota yang baik agar dapat memenangkan permainan. Peningkatan pun terjadi pada daya ingat siswa, kemampuan berpikir cepat, serta kepedulian pada anggota lain agar semua siswa dalam kelompok dapat memahami materi agar dapat menjawab kartu pertanyaan pada Dory.

\section{SIMPULAN}

Permainan Dory yang diterapkan oleh peneliti ternyata mendapatkan respon positif dari siswa. Siswa merasa pembelajaran sejarah yang dilakukan dengan permainan Dory membuat suasana belajar tidak kaku dan membantu siswa agar tetap fokus. Respon positif tersebut mampu membuat penerapan media permainan Dory di kelas XI IPS 3 SMA Negeri 7 Bandung berjalan efektif dan efisien. Efektifnya penerapan media permainan Dory membuat Dory mampu meningkatkan pemahaman konsep siswa kelas XI IPS 3 SMA Negeri 7 Bandung dalam pembelajaran sejarah. Kemudian terdapat temuan lain yang teramati oleh peneliti selama penerapan media permainan Dory, yaitu penerapan media permainan Dory mampu memberikan manfaat lain bagi siswa kelas XI IPS 3, di antaranya adalah menambah kemampuan mengingat siswa, melatih kemampuan berfikir secara cepat dan tepat, melatih kemandirian siswa dalam mempelajari materi, menumbuhkan rasa empati terhadap anggota kelompok. Alat musik Angklung Gubrag sudah digunakan sejak lama oleh masyarakat Cigudeg sebagai media ritual dalam upacara Seren Taun yang bertujuan untuk memuja Nyi Pohaci. Penggunaannya

\section{DAFTAR PUSTAKA}

Alvionita, H. Penggunaan Media dalam Pembelajaran Sejarah SMA di Kabupaten Semarang Tahun Ajaran 2014/2015. Indonesian Journal of History Education. 3 (2), hlm. 31 - 35. Antopani, H. (2016). Penggunaan Media Time Line untuk Meningkatkan Kemampuan Berpikir Krobologis Siswa dalam Pembelajaran Sejarah (Penelitian Tindakan di Kelas XI IIS 1 SMA Negeri 11 Bandung). (Skripsi). Fakultas Pendidikan Ilmu Pengetahuan Sosial. Uniersitas Pendidikan Indonesia, Bandung.

Arikunto, S. (2008). Penelitian Tindakan

Kelas. Jakarta: Bumi Aksara

Erlandini, Y. C. (2017). Efektivitas Teknik

Permainan Puzzle dalam Pemahaman Konsep Pembelajaran IPS di SMP Negeri 40 Bandung. (Skripsi). Fakultas Pendidikan Ilmu Pengetahuan Sosial. Uniersitas Pendidikan Indonesia, Bandung.

Falahudin, I. (2014). Pemanfaatan Media dalam Pembelajaran. Jurnal Lingkar Widyaiswara. 1 (4), hlm. 104 - 117.

Fauziah, I. (2017). Efektivitas Penggunaan Media Board Game terhadap Pemahaman Konsep Mata Pelajaran IPS. (Skripsi). Fakultas Pendidikan 
NURUL HASANAH KUSUMAH DEWI DAN WAWAN DARMAWAN

LUDO HISTORY (DORY) DALAM PEMBELAJARAN SEJARAH DI SMA NEGERI 7 BANDUNG

Ilmu Pengetahuan Sosial. Universitas Pendidikan Indonesia

Hafid, Abd. (2011). Sumber dan Media Pembelajaran. Sulesena. 6 (2), hlm. 69 -78 .

Hasan, H, dkk. (2011) Buku ajar penelitian pendidikan sejarah. Jurusan Pendidikan Sejarah Fakultas Pendidikan Ilmu Pengetahuan Sosial Universitas Pendidikan Indonesia Bandung.

Kunandar. (2012). Langkah Mudah Penelitian Tindakan Kelas sebagai Pengembangan Profesi Guru. Jakarta: Rajawali Pers
Maimunah. (2016). Metode Pnggunaan Media Pembelajaran. Jurnal Al-Afkar. 5 (1), hlm. $1-23$

Muslich, M. (2009). Melaksanakan PTK itu Mudah (Classroom Action Research): pedoman praktis bagi guru professional. Jakarta: Bumi Aksara

Smaldino, A. E., dkk (2008). Instructional Technology \& Media for Learning (Teknologi Pembelajaran dan Media untuk Belajar). Jakarta: Kencana

Tendrita, M., dkk. (2016). Peningkatan Aktiivitas Belajar dan Pemahaman Konsep Biologi dengan Strategy Survey, Question, Read, Recite, Review (SQ3R). Varia Pendidikan. 28, (2), hlm. $213-224$. 
FACTUM

Volume 8 No.2, Oktober 2019 